\title{
Transversalidade de gênero: uma análise sobre os significados mobilizados na estruturação da política para mulheres no Brasil
}

\author{
Mariana Mazzini Marcondes \\ Fundação Getúlio Vargas (FGV-SP) \\ Ana Paula Rodrigues Diniz \\ Fundação Getúlio Vargas (FGV-SP) \\ Marta Ferreira Santos Farah \\ Fundação Getúlio Vargas (FGV-SP)
}

A criação da Secretaria de Políticas para as Mulheres representou um marco na estruturação da política para mulheres e igualdade de gênero no Brasil. A transversalidade de gênero foi adotada como estratégia de atuação nesse processo, envolvendo um conjunto de instrumentos, organismos, instâncias e mecanismos de gestão e participação social. Neste artigo, investigamos os significados atribuídos à transversalidade, focalizando a estruturação da política para mulheres e igualdade de gênero no Executivo Federal. A partir da análise de documentos, fundamentada no arcabouço teórico proposto por Walby (2005), concluímos que esses significados são indissociáveis das principais questões do feminismo, transbordando a dimensão da gestão governamental. Nesse contexto, os contornos da transversalidade são redefinidos, tanto diante dos desafios de institucionalização da política, quanto pelas disputas e negociações travadas no campo feminista.

Palavras-chave: gênero - mulher, políticas públicas - Brasil, institucionalização

[Artigo recebido em 15 de julho de 2017. Aprovado em 24 de abril de 2018.] 
Transversalidad de género: un análisis acerca de significados movilizados en la estructuración de políticas para mujeres en Brasil

La creación de la Secretaría de Políticas para las Mujeres representó un marco para la institucionalización de políticas para las mujeres e igualdad de género en Brasil. La transversalidad de género fue adoptada como estrategia de acción en eso proceso, involucrando un conjunto de instrumento, organismos, instancias y mecanismos de gestión y participación social. En este artículo, investigamos los significados atribuidos a la transversalidad, enfocando la estructuración de la política para las mujeres e igualdad de género en el ejecutivo federal. A partir de los análisis documentales, basada en el estudio de Walby (2005), concluimos que esos significados son indisociables de las principales cuestiones del feminismo, desbordando la dimensión de la gestión gubernamental. En ese contexto, los contornos de la transversalidad se redefinen, tanto por los desafíos de la institucionalización de la política, cuanto por disputas y negociaciones del campo feminista.

Palabras clave: género - mujer, políticas públicas - Brasil, institucionalización

\section{Gender mainstreaming: a discussion on the meanings mobilized throughout the structuring of policies for women in Brazil}

The establishment of the Secretariat of Public Policy for Women was a landmark in the structuring of policies for women and gender equality in Brazil. In this process, the gender mainstreaming was adopted as a strategy of governmental intervention, comprising a set of agencies and instruments of public management with societal participation. In this paper, we investigate the meanings given to the gender mainstreaming strategy, focusing on the structuring of policies for women and gender equality on the federal government. Based on the analysis of documents, and departing from the framework proposed by Walby (2005), we conclude that these meanings are indissociable of the main questions of feminism, going beyond the management dimension. In this context, the content of the gender mainstreaming strategy is redefined in front of challenges faced throughout the policy institutionalization, as well as the struggles and negotiations established within the feminist field.

Keywords: gender - woman, public policies - Brazil, institutionalization 


\section{Introdução}

Políticas públicas para mulheres e igualdade de gênero surgiram no Brasil nos anos 1980, no contexto de redemocratização e ressurgimento dos movimentos feministas e de mulheres (FARAH, 2004). No entanto, sua estruturação foi deflagrada a partir de 2003 , com a criação da Secretaria de Políticas para as Mulheres (SPM) e de um conjunto de instrumentos e instâncias para efetivar sua missão ${ }^{1}$. Foram emblemáticos dessa trajetória a Política Nacional para as Mulheres (BRASIL, 2004a; b), os Planos Nacionais de Políticas para as Mulheres (PNPMs) (BRASIL, 2004b; 2008; 2013) e as Conferências Nacionais de Políticas para as Mulheres (CNPM), realizadas periodicamente nas diferentes esferas federativas. Essas novas iniciativas combinaram-se a outras existentes, como o Conselho Nacional de Direitos da Mulher (CNDM), buscando articular gestão e participação social no desenvolvimento de políticas na área.

Nesse percurso, a transversalidade foi desenvolvida como uma estratégia para inserção da perspectiva de gênero no curso da ação estatal (BRASIL, 2004a). Por meio dela, busca-se reorientar as políticas públicas para o objetivo de igualdade de gênero, garantindo melhoria das condições de vida das mulheres (GUZMÁN, 2001; BANDEIRA, 2005; ORgANizAÇÃo dAS NAções UNIDAS MulHereS, 2005; SERRA, 2006). Trata-se da expressão nacional do gender mainstreaming, difundido principalmente a partir da IV Conferência Mundial de Mulheres, realizada em Pequim, em 1995 (BANDEIRA, 2005; PAPA, 2012; REINACH, 2013). Nessa trajetória nacional, a transversalidade ganhou novos contornos, assumindo características contextuais, inclusive como resposta a disputas travadas no campo feminista.

A transversalidade, nos níveis internacional e nacional, tem sido objeto de pesquisas nos campos de administração pública (SERRA, 2006; INSTITUTO DE PESQUISA ECONÔMICA APLICADA , 2009; SILVA, 2011; CUNNIL-GRAU, 2014; MARCondES; SANDIM; DINIZ, 2018) e gênero (JAHAN, 1996; GUZMÁN, 2001; SHAW, 2002; WALBY, 2005; Moser; Moser, 2005; LABReCQUe, 2010; Monteiro, 2013), com aproximações e distanciamentos entre ambos. No Brasil, a reflexão sobre a consolidação de políticas com recorte de gênero, ocorrida nas últimas décadas, tem mobilizado esforços para

\footnotetext{
${ }^{1}$ Utilizamos o termo "instrumentos" para nos referir aos ferramentais norteadores e organizadores das ações governamentais, como políticas e planos; e "instâncias" para designar esferas de articulação e negociação entre agentes governamentais e não-governamentais, a exemplo das conferências, conselhos e comitês. Já “organismos de políticas para mulheres" é a denominação empregada para as unidades de coordenação de políticas públicas para mulheres e para a igualdade de gênero, em todos os níveis federativos. Por fim, o termo "mecanismos" é reservado a institucionalidades criadas no âmbito de órgãos implementadores das iniciativas que compõem a política pública para as mulheres. Enquanto a SPM é um exemplo de organismo, a Diretoria de Políticas para Mulheres Rurais, que existiu no Ministério de Desenvolvimento Agrário, no período analisado, constitui um mecanismo.
} 
a convergência entre esses dois campos (BANDEIRA, 2005; PEREIRA et al., 2010; PAPA, 2012; REINACH, 2013). É com esses esforços que esse trabalho visa contribuir.

Nesse contexto, nosso objetivo é investigar os significados atribuídos à transversalidade no processo de estruturação da política pública para mulheres no Brasil. Para tanto, realizamos uma pesquisa qualitativa, com base na análise de documentos oficiais produzidos ao longo da trajetória de desenvolvimento dessa política no Executivo Federal, no período de 2003 a 2016. Partindo de Walby (2005), argumentamos que os significados atribuídos à transversalidade de gênero são indissociáveis do contexto sócio-político em que essa estratégia se desenvolveu, não se limitando à forma de nomear a gestão dessa política. Com isso, buscamos evidenciar que esses significados não são estáticos, sendo permeados por elementos da dinâmica política nacional, especialmente das disputas e negociações do campo feminista.

Este artigo está organizado em seis seções, incluindo esta introdução e as considerações finais. Na segunda seção, debatemos o conceito de transversalidade de gênero para, em seguida, apresentarmos a metodologia de pesquisa. A quarta seção abrange o histórico de estruturação da política para mulheres e igualdade de gênero no Brasil, e a quinta, por fim, é dedicada à análise dos significados atribuídos à transversalidade de gênero nesse percurso.

\section{Transversalidade de gênero: origens e principais questões de um conceito em disputa}

Desde os anos 1970, observa-se a crescente reivindicação por parte dos movimentos feministas e de mulheres em prol da incorporação da problemática de gênero na ação estatal. Isso tem conduzido a uma atuação mais efetiva de instituições no campo, inclusive de organismos internacionais, que, em coerência com as demandas dos movimentos, têm recomendado que Estados Nacionais promovam políticas para a superação dessas desigualdades. Desde a I Conferência Mundial de Mulheres, realizada no México em 1975, essas recomendações foram apresentadas. No entanto, ainda que diversos países tenham se comprometido a cumpri-las, poucos esforços foram empreendidos no período (BANDEIRA, 2005).

Nesse contexto, nos anos 1980, movimentos feministas e de mulheres europeus impulsionaram debates sobre políticas e estratégias para efetiva incorporação da perspectiva de gênero no curso da ação estatal, resultando no desenvolvimento do gender mainstreaming. A partir da IV Conferência Mundial de Mulheres, realizada em Pequim, em 1995 (SERRA, 2006; REINACH; 2013; PAPA, 2012), essa estratégia foi difundida internacionalmente, visando assegurar que a perspectiva 
de gênero integre as políticas desenvolvidas em todas as esferas de atuação estatal (ORganização dAS NAções UnidAS - MulHeRES, 1995; BANDEIRA, 2005). Desde então, o gender mainstreaming tem sido adotado nos níveis internacional, regional, nacional e subnacional (SHAW, 2002; WALBY, 2005; LABRECQUE, 2010; PAPA, 2012; REINACH, 2013).

A incorporação da perspectiva de gênero na ação estatal tem sido acompanhada pela produção acadêmica sobre o tema, tanto no campo de administração pública quanto dos estudos de gênero e, ainda, na convergência entre ambos. No primeiro, a transversalidade é recorrentemente associada à coordenação governamental das ações de diferentes setores, em decorrência da introdução de novos temas sobretudo referentes à garantia de direitos - que não integravam a missão de um órgão em específico, mas que pressupõem uma visão integral para a efetividade da atuação estatal (SERRA, 2006; CUNNIL-GRAU, 2014). Sua abrangência é, contudo, objeto de controvérsias, especialmente na delimitação de fronteiras com outros conceitos, como o de intersetorialidade, o que tem resultado no uso intercambiável de ambos (Bronzo, 2007; INSTITUto de Pesquisa Econômica Aplicada, 2009; Silva, 2011; MARCONDES; SANDIM; DINIZ, 2018).

Os estudos de gênero, por sua vez, incorporam a preocupação com a operacionalização da transversalidade, mas priorizam suas conexões com questões fundamentais do feminismo, em suas permanentes disputas (WALBY, 2005). Como discute Guzmán (2001), a incorporação da perspectiva de gênero na gestão pública envolve a legitimação dessa problemática na sociedade e no Estado, com sua integração à agenda governamental, resultando na institucionalização de políticas públicas para sua superação. Trata-se de um processo conflituoso, no qual os significados atribuídos à transversalidade se transformam, em decorrência de fatores culturais, institucionais, espaciais e temporais (GUZMÁN, 2001; WALBY, 2005). Nesse sentido, essa incorporação não constitui uma simples tradução da expressão gender mainstreaming, mas implica sua (re)construção contextual, em que uma multiplicidade de significados é mobilizada em distintos países, organismos internacionais e movimentos feministas e de mulheres.

Walby (2005) propõe que a transversalidade seja analisada em torno de cinco questões. Primeiramente, deve-se considerar a existência de um conflito inerente à relação entre o objetivo de igualdade de gênero e o curso da ação estatal, decorrente da contraditória relação entre feminismo e Estado. Como destacam Cisne e Gurbel (2008), por um lado, a incorporação de reivindicações feministas pelas políticas públicas contribui para a garantia de direitos. Por outro, essa pode gerar a despolitização da luta social, com a perda da radicalidade da agenda dos movimentos feministas para adequar-se às rotinas governamentais (JAHAN, 1996). Trata-se do 
que Guzmán (2001, p. 23) denomina “contrapartida da institucionalização", em que as reivindicações feministas são ajustadas às regras constitucionais e legais e, ainda, à lógica da ação estatal, como parte do processo de institucionalização.

A proposição de um Estado promotor da igualdade de gênero conflita, ainda, com a orientação historicamente consolidada para o curso de sua ação, comprometida com a reprodução de desigualdades, em geral, e do patriarcado, em particular. Nesse contexto, Shaw (2002) salienta que o compromisso com a igualdade de gênero pode ser incorporado à dinâmica de ação estatal de forma integrada ou marginalizada. No primeiro caso, esse conflito resultaria na reorganização do curso da ação estatal, orientando-se pelo objetivo da igualdade de gênero. No segundo, esse objetivo seria acoplado à dinâmica existente, sem reestruturá-la.

Por fim, outro desdobramento diz respeito à adoção de uma compreensão instrumental do objetivo de igualdade (MOSER; MOSER, 2005), em que esse não constitui um fim em si mesmo, mas um meio para potencializar outros objetivos estratégicos do Estado, como o desenvolvimento econômico e o combate à pobreza (FARAH, 2004). Embora essas perspectivas sejam conciliáveis, a instrumentalização dissociada de uma perspectiva de gênero pode contribuir para legitimar desigualdades e estereótipos. É ilustrativa a crítica que a literatura feminista vem tecendo aos programas de transferência de renda condicionada, nos quais as mulheres são vistas menos como beneficiárias principais e mais como vetores de eficiência do gasto público, ao ser instrumentalizado seu tradicional papel de cuidadora dentro das famílias para o cumprimento dos objetivos desses programas (CARLOTO; MARIANO, 2012).

Das tensões resultantes da institucionalização da problemática de gênero decorre uma segunda questão, em que a transversalidade é conformada prioritariamente como um processo técnico, manipulável por meio de um conjunto de instrumentos neutros, ou como um processo de democratização do Estado, em que vozes e interesses até então invisíveis são incorporados ao processo político. Embora essa tensão não seja uma particularidade do feminismo, ela assume contornos específicos nesse campo (WALBY, 2005).

A dimensão política e democratizante relaciona-se com uma visão crítica e posicionada sobre o mundo, a partir da qual as formas de operacionalização técnica devem ser ressignificadas, de modo a contribuir para o alcance da igualdade de gênero (WALBY, 2005). Assim, denuncia-se qualquer pretensão de neutralidade das políticas e de suas técnicas gerenciais e operacionais, afirmando-se que essas impactam na reprodução ou transformação das desigualdades. Nesse sentido, a dimensão técnica e especializada - que abrange os meios gerenciais para a operacionalização das políticas na área - não pode ser negligenciada, uma vez 
que a transversalidade, como um objetivo, deve ser traduzida em um processo (MOSER; MOSER, 2005). Para tanto, a operacionalização da transversalidade deve envolver o desenvolvimento de instrumentais que subsidiem o planejamento, a implementação e o monitoramento de políticas públicas, incluindo o planejamento e a execução orçamentária e a formação de profissionais.

A constituição de instâncias que garantam a responsabilização das estruturas governamentais e agentes do sistema político é, por conseguinte, igualmente importante, a fim de "retirar as questões da igualdade dos 'guetos de igualdade"" (MONTEIRo, 2013, p. 540). Para isso, também contribuem a criação de organismos de políticas para mulheres que coordenem esse processo (GUZMÁN, 2001), assim como de mecanismos que reverberem essas diretrizes no âmbito de outros órgãos. Por fim, especialmente considerando a importância dos movimentos feministas e de mulheres para impulsionar a institucionalização de políticas com recorte de gênero, é fundamental que essa articulação de instâncias, instrumentos, organismos e mecanismos incorpore a participação social, garantindo a democratização da ação estatal.

Uma terceira questão emerge das diferentes concepções de gênero que podem fundamentar o modelo de transversalidade, conforme elas se aproximem mais das noções de "igualdade", "diferença" ou "transformação" (WALBY, 2005). Essa diferenciação remete a um debate fundamental do feminismo: a tensão entre igualdade e diferença (FRASER, 2009; MIgUEL, 2014).

A matriz da igualdade identifica na desigualdade das mulheres em relação aos homens o cerne da problemática, principalmente em relação ao desigual acesso a direitos e posições de emprego e poder na esfera pública. Uma crítica a essa formulação, postulada a partir da perspectiva da diferença, é que a ênfase na igualdade deixa de valorizar aquilo que as mulheres historicamente fazem, como a maternidade e o cuidado, contribuindo para legitimar o sujeito masculino como o padrão universal (FRASER, 2009; MIGUEL, 2014).

Por outro lado, o feminismo da diferença é recorrentemente criticado por essencializar o feminino e reafirmar estereótipos de gênero, como a vinculação entre feminilidade, maternidade e cuidados. Uma alternativa a ambas - ou, ainda, a uma mera combinação de ambas - é a postulação de uma concepção transformadora das relações de gênero, em que a ênfase seja deslocada das mulheres para o elemento relacional de gênero, e que aborde também as masculinidades (FRASER, 2009; Miguel, 2014; FARAH, 2015).

A diferença pode, ainda, ter outro significado crítico, a partir do qual se aponta a necessidade de articular outras relações e identidades às relações de gênero, o que nos remete à quarta questão (WALBY, 2005). Essa articulação pode ser 
compreendida por meio do conceito de interseccionalidade ${ }^{2}$, que, de acordo com Crenshaw (2002, p. 4), implica "que se dê atenção às várias formas pelas quais o gênero intersecta-se com uma gama de outras identidades e ao modo pelo qual essas intersecções contribuem para a vulnerabilidade particular de diferentes grupos de mulheres". A interseccionalidade é perpassada por tensões. Se, por um lado, ela permite questionar o sujeito universal feminino, fonte de opressões entre as mulheres (CRENSCHAW, 2002), o reconhecimento de múltiplas identidades implica fragmentações que trazem desafios à constituição de políticas públicas que beneficiem a totalidade desses sujeitos.

Por fim, um quinto aspecto refere-se às implicações transnacionais do desenvolvimento da transversalidade de gênero, em um contexto de conflitos entre o nacional, o local e o global, no qual disputas teóricas e políticas sobre o processo de globalização devem ser consideradas (WALBY, 2005).

\section{Metodologia}

A fim de compreendermos os significados atribuídos à transversalidade de gênero no processo de estruturação da política para as mulheres no Brasil, de 2003 a 2016, partimos de quatro das questões identificadas por Walby (2005), sistematizadas na Figura 1.

Figura 1 - Tensões constitutivas da transversalidade de gênero

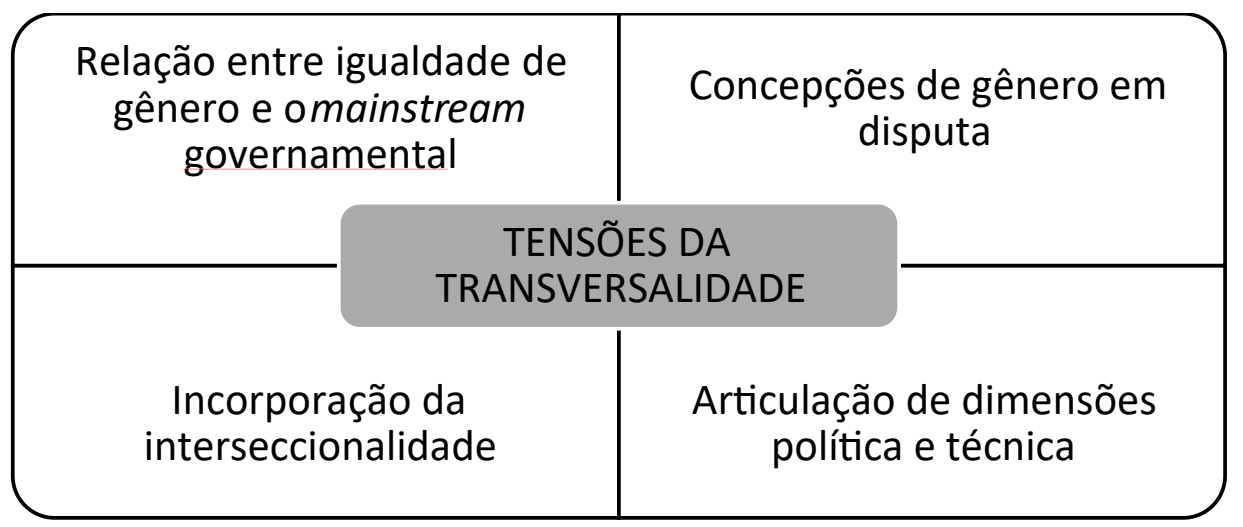

Fonte: Elaboração própria, a partir de Walby (2005) e Crenshaw (2002)

Partindo desse enquadramento, foi realizada uma pesquisa qualitativa (GIBBS, 2009), com análise de documentos produzidos pela SPM. A escolha desses

2 Partindo de matrizes teóricas e políticas distintas, outras autoras, como Kergoat (2010), utilizam o termo consubstancialidade. Para uma reflexão sobre as aproximações e distanciamentos entre esses dois conceitos, remetemos a essa autora. 
documentos orientou-se pelo critério de relevância para a compreensão de instrumentos de estruturação da política para mulheres em nível federal, a exemplo da Política Nacional (BRASIL,, 2004b) e das três edições do PNPM (BRASIL, 2004b; 2008; 2013), enfatizando-se como abordam a transversalidade e a proposta de sua operacionalização. Pelas mesmas razões, analisamos as orientações para criação de mecanismos de gênero no Governo Federal (BRASIL, 2014a), por entendê-las como parte central dessa estratégia.

Também foram selecionados documentos que retratassem o processo da CNPM, dada a importância que essa instância de participação social assumiu no desenvolvimento da Política Nacional e dos PNPMs. Foram considerados os decretos convocatórios (BRASIL, 2003; 2007b; 2011a; 2015a), os regimentos internos (BRASIL, 2004a; 2007b; 2011b; 2015b), o texto base da quarta edição (BRASIL, 2015c) e os anais das três primeiras Conferências (BRASIL, 2004a; 2007a; 2011a). Nos últimos, enfocamos as resoluções do processo participativo e as falas de representantes governamentais e do CNDM, órgão diretamente envolvido na coordenação e articulação de políticas para as mulheres em âmbito federal.

Por fim, buscamos incorporar documentos que permitissem compreender a integração da perspectiva interseccional. Para isso, enfocamos o Relatório Final do Grupo de Trabalho para Fortalecimento das Ações de Enfrentamento ao Racismo, Sexismo e Lesbofobia no II PNPM (BRASIL, 2010b), além de seções e trechos referentes ao tema presentes nos documentos anteriormente citados. É importante destacar, nesse contexto, que a pesquisa se concentrou nos sentidos atribuídos à transversalidade no processo de (re)formulação da política, não contemplando o cotidiano de sua implementação.

A apresentação dos resultados integra as duas próximas seções. Primeiramente, introduzimos o histórico de estruturação da política para mulheres e igualdade de gênero no Brasil, com destaque para o período posterior à criação da SPM, em que a temática da transversalidade ganhou maior centralidade na agenda governamental. Depois, discutimos seus significados, construídos e reconstruídos nessa trajetória.

A crítica feminista foi adotada como ponto de partida para desenvolvimento deste trabalho. Na perspectiva assumida, o gênero é visto como "elemento constitutivo de relações sociais baseado nas diferenças percebidas entre os sexos, e [...] uma forma primeira de significar as relações de poder" (SCOTT, 1995, p. 21). A compreensão - e superação - dessa forma de desigualdade envolve tanto as dinâmicas de opressão entre mulheres e homens, quanto a articulação das desigualdades de gênero com outras formas de desigualdade (CRENSHAW, 2002), como as de classe, raça, etnia, orientação sexual e identidade de gênero. 
Nesse sentido, partimos do questionamento da oposição binária entre feminino e masculino (LouRo, 1997), reconhecendo que "a" mulher e "o" homem são categorias ao mesmo tempo "vazias e transbordantes". Vazias, pois não possuem um significado fixo e definitivo; e transbordantes, porque são constantemente ressignificadas, social, histórica e politicamente (ScotT, 1995, p. 11).

\section{A estruturação da política para as mulheres e para a igualdade de gênero no Brasil: práticas de transversalidade}

Embora políticas com recorte de gênero sejam implantadas no Brasil desde os anos 1980 (FARAH, 2004), foi a partir da criação da SPM³, no primeiro ano de governo de Luís Inácio "Lula" da Silva, que essas políticas ganharam maior institucionalidade. A secretaria, inicialmente dotada de status ministerial, assumiu a competência de coordenação, articulação e monitoramento de políticas na área (BRASIL, 2003). A instituição de um organismo de políticas para mulheres, situado em alto nível hierárquico e com competências claras e recursos próprios, atendia tanto a reivindicações dos movimentos feministas e de mulheres, quanto a recomendações internacionais. Expressava, também, a especificidade do percurso nacional, para o qual eram relevantes experiências anteriores de governos subnacionais (PAPA, 2012), inclusive durante governos prévios do Partido dos Trabalhadores (PT), que então chegara ao poder em nível federal.

Como mencionado, seguindo as recomendações da Plataforma de Ação de Pequim, a SPM adotou a transversalidade de gênero como estratégia para sua atuação (PAPA, 2012). A criação e reestruturação de outros órgãos em nível federal com base no princípio da transversalidade também contribuíram para a disseminação dessa estratégia na prática governamental. É o caso da Secretaria de Políticas de Promoção da Igualdade Racial (SEPPIR) e da Secretaria Nacional da Juventude (SNJ), instituídas em 2003; e da Secretaria de Direitos Humanos (SDH), criada nos anos 1990 e reorganizada em 2005 (PAPA, 2012; REINACH, 2013).

A materialização da transversalidade de gênero no contexto nacional não se restringiu à criação de um organismo de política para mulheres. Ao revés, desenvolveu-se um conjunto de instâncias, instrumentos e mecanismos de gestão e participação social que, articulados, visaram traduzir o objetivo de transversalidade em um processo (MOSER; MOSER, 2005).

\footnotetext{
${ }^{3}$ Em 2002, último ano do segundo governo de Fernando Henrique Cardoso, foi criada a Secretaria de Estado dos Direitos da Mulher (SEDIM), vinculada ao Ministério da Justiça (BRASIL, 2010a). Entretanto, sua vigência foi curta e, mesmo durante esse período, não foram garantidas plenas condições para sua efetivação enquanto um órgão governamental (BANDEIRA, 2005; PAPA, 2012).
} 
No que diz respeito à participação, isso implicou a reestruturação de instâncias pré-existentes. Criado nos anos 1980, o CNDM passou a integrar a estrutura da SPM, sendo- Ihe designadas atribuições típicas de um conselho de políticas públicas, a exemplo da formulação de diretrizes para essas políticas (BRASIL, 2003). Foram criadas também novas instâncias, como a CNPM, fundamental para a consolidação desse processo de transversalidade com participação.

A 1a CNPM, realizada em 2004, buscou propor diretrizes para a fundamentação de dois importantes instrumentos. O primeiro deles foi a Política Nacional, instituída para ser "a linha mestra das diferentes ações que integram os planos nacionais" (BRASIL, 2008, p. 27). O segundo, o PNPM, com a finalidade de estabelecer ações governamentais para "conjunturas específicas".

O I PNPM foi composto por 199 ações, organizadas em cinco capítulos, sendo quatro temáticos e um dedicado à gestão e ao monitoramento do Plano. Para viabilizar sua gestão, foi criada outra instância, de gestão da política, denominada Comitê de Articulação e Monitoramento do PNPM. Ele foi composto pelo CNDM e mais 11 órgãos governamentais, incluindo a SPM, responsável por sua coordenação (BRASIL, 2008)4. A instituição desse comitê buscou responder principalmente ao desafio de "integração entre os órgãos setoriais na definição e tratamento da transversalidade" (BRASIL, 2004b, p. 76).

Nesse momento, foram lançadas as bases para estruturação da transversalidade na experiência do Governo Federal. Ela articulou instrumentos definidores do compromisso governamental em longo e médio prazo (Política Nacional e PNPM) com instâncias de participação social (Conferências e CNDM) e de gestão, articulação e monitoramento das políticas para as mulheres (Comitê de Articulação e Monitoramento).

Seguindo o percurso realizado na edição anterior, a 2a CNPM objetivou "analisar e repactuar os princípios e diretrizes aprovadas na 1․ CNPM e avaliar a implementação do I PNPM" (BRASIL, 2007c, p. 9) em todos os níveis federativos. A partir da identificação de avanços e desafios, buscou-se acordar modificações necessárias para a elaboração de um novo plano. Nesse sentido, o II PNPM foi desenvolvido com base nas resoluções da segunda conferência, no Plano Plurianual (2008-2011) e na Agenda Social do Governo Federal, sob a coordenação da SPM (BRASIL, 2008).

O número de ações, eixos e temas tratados foi ampliado, incorporando 388 ações, 94 metas e 56 prioridades, organizadas em 12 capítulos, sendo oito setoriais,

\footnotetext{
${ }^{4}$ Na primeira versão do decreto de instituição, publicada em 08 de março de 2005 , essa era a composição. Entretanto, em 20 de maio do mesmo ano foi incluído o Ministério de Minas e Energia, o que resultou em 12 órgãos governamentais, além do Conselho.
} 
dois dedicados a múltiplas formas de desigualdades, um reservado à gestão e monitoramento e outro à previsão orçamentária. O Comitê também foi ampliado, sendo composto por representações do CNDM, dos organismos municipais e estaduais de políticas para as mulheres e de 19 órgãos e entes governamentais federais (BRASIL, 2008).

A convocação da 3ạ CNPM também previu, entre seus objetivos, o estabelecimento de prioridades e propostas a partir da avaliação e aprimoramento do II PNPM. Nesse sentido, nas três primeiras edições das CNPMs e PNPMs, observou-se o estabelecimento de uma dinâmica cíclica entre: $i$. realização da Conferência para, por meio da participação social, definir diretrizes e identificar reivindicações e propostas; ii. formulação e implementação de uma edição do PNPM, articulando um conjunto de ações e mobilizando outros setores e entes da federação; e iii. avaliação do Plano em uma nova Conferência, na qual são indicadas novas diretrizes, reivindicações e propostas.

Nessa edição da CNPM, foi conferida especial visibilidade às conferências subnacionais. Entre seus objetivos, destacou-se a importância de que as etapas municipais, distritais e estaduais contribuíssem para a proposição de uma plataforma de políticas para as mulheres e para o fortalecimento de institucionalidades de gênero em seus respectivos âmbitos (BRASIL, 2011a). A inclusão desses objetivos sinaliza um esforço de ampliação da capilaridade dessas políticas públicas. Esse esforço pode ser associado aos desafios de implementação das ações em nível subnacional, mas também ao de consolidação da política, em um contexto de risco de extinção da SPM.

A terceira edição da Conferência foi realizada durante o primeiro governo da presidenta Dilma Rousseff. Nessa conferência, havia uma suspeita, disseminada entre as participantes, de que o novo governo poderia criar um único órgão ministerial que fundisse todas as pastas ditas transversais (direitos humanos, política para as mulheres, igualdade racial e juventude). Isso levou a então presidenta a afirmar em seu discurso de abertura da Conferência, que: "Muitas vezes vocês veem nos jornais ser anunciado que o Ministério - que é a Secretaria de Políticas para as Mulheres vai, simplesmente, ser fechado ou unido a outro. Não há a menor veracidade [nessa afirmação]" (BRASIL, 2011a, p. 11).

O terceiro plano nacional, denominado PNPM (2013-2015), atualizou o anterior e incorporou novas temáticas. A composição do Comitê também foi modificada, passando a contar com 33 órgãos governamentais, incluindo a SPM, e três representações do CNDM (BRASIL, 2013).

Em relação à sua gestão, foi enfatizada a "consolidação de mecanismos de gênero nos órgãos e ministérios" (BRASIL, 2013, p. 12). Isso se daria por meio da 
criação de diretorias, coordenadorias ou assessorias que respondessem pela implementação de ações que integrassem a política para as mulheres em diferentes órgãos governamentais. Com isso, buscava-se responsabilizar esses órgãos e entes governamentais, além de fortalecer a coordenação transversal da SPM.

Finalmente, a 4a CNPM, realizada entre 2015 e 2016, teve como objetivo geral fortalecer a Política Nacional para as Mulheres. Essa previu dez objetivos específicos, entre os quais se destacaram a promoção da participação da sociedade civil na execução e controle da Política; o fortalecimento de organizações feministas e de conselhos dos direitos das mulheres; o estímulo à criação e fortalecimento de organismos de políticas para as mulheres na esfera subnacional e de planos municipais, estaduais, distritais e nacionais para a estruturação das ações na área; e a apresentação de um balanço da implementação do PNPM (2013-2015) (BRASIL, 2015a; b; c).

Nesse contexto, observamos que, ainda que o PNPM seja citado, a incorporação desses novos objetivos indica uma alteração na dinâmica cíclica entre a realização das conferências e a formulação, implementação e avaliação da política e dos planos nacionais. Como evidenciado no Caderno de Propostas (BRASIL, 2015), não se tratava mais de reelaborar o Plano Nacional. A quarta conferência deveria orientar-se para o fortalecimento de estruturas institucionais e de instrumentos para promoção de políticas na área, enfatizando-se as relações entre os entes federativos e entre a sociedade civil e o Estado. A medida desse desafio pode ser ilustrada pelo número de organismos de políticas para as mulheres existentes em nível subnacional. Em 2014, existiam 680 organismos de políticas para as mulheres no país, sendo 24 estaduais e 656 municipais (BRASIL, 2014b).

Nesse sentido, essa edição enfatizou a coleta de subsídios para construção de um Sistema Nacional de Políticas para as Mulheres em seu temário. A constituição de sistemas é uma tendência na coordenação federativa de outras áreas de políticas públicas, como o Sistema Único de Saúde e o Sistema Único de Assistência Social (FRANZESE, 2010) e, mais recentemente, do Sistema Nacional de Promoção da Igualdade Racial (BRASIL, 2010). É, ainda, uma tendência entre as conferências nacionais de diferentes áreas, especialmente para reivindicar a vinculação de receitas ao cumprimento de seus objetivos, com a criação de fundos específicos (SOUZA, 2013).

Observamos, contudo, que o contexto de forte instabilidade política, econômica e institucional no país impactou esse processo. A fusão das secretarias entendidas como transversais ocorreu antes do início das primeiras etapas da 4a CNPM, no primeiro ano do segundo governo da presidenta Dilma Rousseff, em que foi criado o Ministério das Mulheres, Igualdade Racial e Direitos Humanos (BRASIL, 2015). A 
etapa nacional da 4a CNPM, por sua vez, foi realizada durante o julgamento, pelo Senado, de admissibilidade do processo de impeachment da então presidenta. Durante o governo do presidente Michel Temer, sucessivas mudanças no desenho organizacional foram empreendidas e, desde 31 de maio de 2017, a Secretaria Nacional de Políticas para as Mulheres compõe a Secretaria de Governo da Presidência da República (BRASIL, 2017).

\section{Os significados da transversalidade de gênero na estruturação da política para mulheres e igualdade de gênero}

A construção e a transformação dos significados atribuídos à transversalidade de gênero inserem-se na trajetória de estruturação da política para as mulheres, correspondente ao período estudado. É em relação a esse contexto que mobilizamos o enquadramento teórico anteriormente apresentado, buscando, inicialmente, evidenciar as concepções de gênero incorporadas à política analisada para, em seguida, debatermos suas conexões com o significado atribuído à transversalidade.

\section{Concepções de gênero em disputa}

Embora a transversalidade seja afirmada nos instrumentos para promoção e gestão da política para mulheres, a concepção de gênero que a baseia não é explicitada. Contudo, a nomenclatura adotada nas Conferências, na Política e nos Planos Nacionais - "para as mulheres" - sugere que são elas que constituem o sujeito para o qual essa se orienta, o que é reforçado pelo nome do organismo: Secretaria de Políticas para as Mulheres.

A opção pela política para mulheres como um caminho para construção da igualdade de gênero depreende-se também das iniciativas previstas nos Planos Nacionais, a exemplo daquelas previstas para a promoção da autonomia econômica e igualdade no mundo do trabalho. No I PNPM priorizou-se a promoção de medidas não discriminatórias e de ampliação do acesso de mulheres ao mercado de trabalho e a formas de geração de renda (BRASIL, 2004b). No II PNPM, essas ações também foram previstas, sendo acrescentadas iniciativas que reconheceram as especificidades dos papéis socialmente exercidos por mulheres, como a aposentadoria de donas de casa, e, ainda, a ampliação da licença maternidade (BRASIL, 2008).

As ações citadas, que trazem ora a perspectiva da igualdade, ora da valorização da diferença, não explicitam como podem contribuir para a transformação da relação de gênero. Além disso, há poucas iniciativas voltadas aos homens e às masculinidades, como seria o caso de licenças paternidade e parental, citadas no 
PNPM (2013-2015) em uma única ação (BRASIL, 2013). Isso reforça a percepção de que a concepção de gênero orientadora da política no período não corresponde àquela denominada "transformadora", na qual se enfatiza o elemento relacional e a masculinidade (WALBY, 2005; FRASER, 2009).

Essa questão remete a uma possível distinção entre políticas para mulheres e para igualdade de gênero. Políticas para mulheres podem ser compreendidas como aquelas que têm as mulheres como beneficiárias exclusivas ou prioritárias, podendo estar ou não comprometidas com a igualdade de gênero (FARAH, 2004; BANDEIRA, 2005). Em alguns casos, essas se ancoram em representações tradicionais e heteronormativas das mulheres, instrumentalizando esse enfoque para garantir a eficiência de políticas públicas, como visto anteriormente. Em outros, a ênfase nas políticas para mulheres é compreendida como uma tática para a construção da igualdade de gênero. Como exemplifica Godinho (2004, p. 58) ao referir-se ao enfoque da então Coordenadoria das Mulheres de São Paulo: "do ponto de vista do resultado da ação, é fundamental orientar-se para o desenvolvimento de políticas concretas dirigidas às mulheres".

Embora a política para mulheres possa ser compreendida como uma condição para a efetivação da igualdade de gênero, como no caso da experiência brasileira no período, ela não necessariamente incorpora a complexidade de uma abordagem transformadora. Essa última poderia ser mobilizada para incorporação dos homense das masculinidadese, de outro, contribuir para a construção de novas representações sociais de gênero que, inclusive, não reafirmassem a heterossexualidade como norma. Essa observação nos remete à outra tensão da transversalidade de gênero, a interseccionalidade.

\section{Incorporação da interseccionalidade}

Outra questão que se transformou no processo de consolidação da política para mulheres diz respeito à articulação de múltiplas formas de desigualdades, com permanente ampliação dos sujeitos considerados nas ações propostas. Isso reflete um esforço, identificado desde a primeira Conferência, de valorização da diversidade e reconhecimento das diferentes formas de desigualdade na Política Nacional. Os princípios orientadores da Política já enfatizavam que a igualdade entre mulheres e homens deve ser construída em respeito e atenção à pluralidade "cultural, étnica, racial, inserção social, de situação econômica e regional, assim como aos diferentes momentos da vida" (BRASIL, 2004b, p. 33), sendo visibilizada a multiplicidade de mulheres, especialmente nas resoluções das conferências e nas ações que compõem os planos. 
Na 1a CNPM e no I PNPM, foi destacada, nos discursos, painéis e resoluções, a importância de considerar as desigualdades raciais e étnicas ao tratar das desigualdades de gênero, o que coincidiu com a criação da SEPPIR, com atribuições relativas a essas duas dimensões (BRASIL, 2004a; b). Na 2a CNPM, as diferenças por orientação sexual e geracionais também ganharam destaque (BRASIL, 2007a; 2008), levando à inclusão de dois eixos relacionados a esses temas no II PNPM: Eixo 9 ("Enfrentamento ao Racismo, Sexismo e a Lesbofobia") e Eixo 10 ("Enfrentamento das desigualdades geracionais que atingem as mulheres, com especial atenção às jovens e idosas"). Na 3a CNPM e no PNPM (2013-2015), passaram a constar referências às mulheres travestis e transexuais e ao combate à transfobia (BRASIL, 2011a; 2013). Na 4a CNPM, as mulheres transexuais e travestis foram consideradas sujeitos da conferência em seus documentos orientadores (BRASIL, 2015a; b; c).

A mudança de abordagem em relação aos sujeitos considerados pela política é fruto, sobretudo, da atuação de movimentos feministas e de mulheres que, nos espaços institucionalizados de participação social, com destaque para as próprias conferências, reivindicavam o reconhecimento de suas diferenças e o desenvolvimento de ações para públicos específicos. Exemplar dessa atuação foi a mobilização realizada por mulheres negras e lésbicas na 2 a CNPM, que culminou na criação do Eixo 9 (BRASIL, 2007a).

A partir do II PNPM, a interseccionalidade foi adotada como um conceito, que evidencia "a impossibilidade de se isolar ou privilegiar na elaboração e gestão de políticas para a equidade, qualquer uma das características que formam indivíduos e grupos" (BRASIL, 2008, p. 171). No PNPM (2013-2015), a articulação de múltiplas formas de desigualdade foi integrada ao próprio conceito de transversalidade, segundo o qual as estruturas e dinâmicas sociais devem ser entendidas em relação à "produção das desigualdades de gênero, raciais, geracionais, de classe, entre outras" (BRASIL, 2013, p. 10).

Essa progressiva articulação entre transversalidade e interseccionalidade não significou, entretanto, a revisão das ações segundo uma perspectiva interseccional. Nos documentos analisados há uma permanente oscilação na abordagem do sujeito da política. Em alguns eixos dos Planos, como o enfrentamento à violência, as ações previstas priorizam a mulher como um sujeito universal, enquanto em outros, como os destinados à saúde, direitos sexuais e reprodutivos e à autonomia econômica e igualdade no mundo do trabalho, evidencia-se maior articulação de diferenças na formulação de ações. 
Relação entre igualdade de gênero e o mainstream governamental

A transversalidade de gênero é identificada, sobretudo no PNPM (2013-2015), como uma "nova estratégia para o desenvolvimento democrático", que significa "a reorganização de todas as políticas públicas e das instituições" (BRASIL, 2013, p. 10). Essa concepção de caráter normativo expressa a transversalidade como reorientadora do curso da ação estatal, aproximando-se mais da incorporação da igualdade de gênero de forma integrada, e não marginalizada (SHAW, 2002).

A efetividade dessa diretriz é, contudo, passível de questionamento. Durante a 2a CNPM, a representante do CNDM, Lia Zanotta, destacou que a "questão das mulheres é vista, em geral, fora da administração do eixo central do Estado", o que torna a "tarefa hercúlea, mas absolutamente frágil" (BRASIL, 2007a, p. 27). As dificuldades de incorporação da transversalidade também foram ressaltadas pelo então ministro da Secretaria Geral da Presidência, Luís Dulci. Segundo ele, quando se "falava em transversalidade no início do nosso governo havia muitos risos e brincadeiras" (BRASIL, 2007a, p. 40). Como se pode depreender desses trechos, a materialização da transversalidade aproxima-se de uma incorporação marginalizada ao curso da ação estatal, ainda que mudanças incrementais sejam indicadas.

$\mathrm{Na} 3$ a CNPM, os limites para a atuação da SPM foram também enfatizados. Realizados em meio à crise econômica de 2008 e ao reaparecimento de discursos neoliberais, seus painéis reiteraram a importância de intervenção estatal para a superação das desigualdades. Reforçaram, também, a necessidade de maior canalização de recursos para o desenvolvimento das ações da Secretaria, o que ficou destacado, sobretudo, na moção de repúdio ao corte orçamentário sofrido, na qual se defende: "Chega de discurso, cadê nossos recursos!" (BRASIL, 2011, p. 113).

Nesse cenário, identificamos uma contradição entre a realidade expressa nas falas - "risos e brincadeiras", "frágil", fora do "eixo central do Estado" - e a afirmação, pelos Planos, especialmente em sua terceira edição, da transversalidade como "a reorganização de todas as políticas públicas e das instituições" (BRASIL, 2013, p. 10). Esse contraste é reforçado pelo fato da SPM, principal organismo para coordenação da transversalidade de gênero, ter sofrido ameaças de perda do status ministerial durante a 3a CNPM, o que se concretizou antes da edição seguinte, ampliando sua fragilidade institucional.

Observamos que a incorporação marginal se aproxima, ainda, de uma abordagem instrumentalizadora da igualdade de gênero (MOSER; MOSER, 2005), na qual a transversalidade é assumida como positiva à medida em que se configura em um meio para alavancar outros objetivos estratégicos. Nesses casos, pode ser inclusive mobilizada para reiterar estereótipos de gênero e, por conseguinte, contribuir para a reprodução de desigualdades. 
A fala da então presidenta Dilma Rousseff durante a 3a CNPM exemplifica essa situação. Nessa oportunidade, ela afirmou que o reconhecimento governamental do "papel estratégico que a mulher ocupa na sociedade" é que o "Bolsa Família, o principal instrumento de distribuição de renda deste país, é recebido pelas mulheres" (BRASIL, 2011a, p. 12). Embora a fala não se refira explicitamente à transversalidade, trata-se de uma expressão de como a questão de gênero é incorporada em algumas ações governamentais como instrumento para alcance de outros objetivos estratégicos, como o enfrentamento à pobreza.

A abordagem instrumentalizadora pode, entretanto, ser um recurso argumentativo na busca pelo deslocamento da questão de gênero de um lugar marginal para o curso central de ação estatal, ao se aproximar dos objetivos governamentais estratégicos. O esforço de legitimação da transversalidade por meio da valorização das dimensões de eficácia e eficiência é emblemático, sendo evidenciado na fala da então ministra Nilcéa Freire, durante a 2a CNPM: "os orçamentos e os gastos públicos são mais eficientes se levarem em consideração as necessidades específicas de mulheres e homens" (BRASIL, 2007a, p. 13).

A marginalidade da transversalidade de gênero não significa, contudo, a inexistência de "contrapartidas da institucionalização" (GuzMÁN, 2001). Um de seus efeitos é uma incorporação menos radical das reivindicações feministas, como exemplifica o tema da descriminalização e legalização do aborto. Ainda que esse problema público tenha sido enfatizado em todas as conferências (BRASIL, 2004a; 2007a; 2011a) e que, nos planos, se ressalte o aborto clandestino como uma importante causa de morte entre as mulheres, as ações contempladas restringemse à ampliação da assistência nos casos previstos em lei, tangenciando a discussão sobre a descriminalização do aborto (BRASIL, 2004b; 2008; 2013). Contudo, sua legalização não é assumida por essa política, ainda que seja uma das principais reivindicações feministas para a garantia de direitos à saúde, sexuais e reprodutivos.

\section{Relações entre as dimensões política e técnica}

A partir da análise dos princípios e diretrizes que compõem a Política Nacional, podemos depreender a dimensão política da transversalidade, em que é afirmada uma visão crítica e posicionada sobre o mundo (WALBY, 2005). Na Política, as desigualdades de gênero são reconhecidas como elementos estruturantes das relações sociais, sustentadas na divisão sexual do trabalho, no controle dos corpos e da sexualidade e na exclusão das mulheres de espaços de poder e de decisão. Reitera-se, ainda, que as ações governamentais participam da construção desse cenário, contribuindo para a reprodução ou transformação das relações desiguais de gênero, raciais, étnicas e relacionadas ao exercício da sexualidade (BRASIL, 2004a; b). 
Na versão original da Política Nacional (BRASIL, 2004a; b), a sua articulação com a estratégia da transversalidade não é explicitada. É na versão contida no PNPM (2013-2015) que a transversalidade é afirmada como "princípio orientador de todas as políticas públicas" (BRASIL, 2013, p. 9). Ainda assim, é possível afirmar que desde a primeira edição da Política e do PNPM essa visão política constituiu o ponto de partida para o desenvolvimento das ações governamentais na área, possuindo forte carga normativa acerca de como deveria ser efetuada a revisão das iniciativas existentes ou a implantação de novas ações.

Os Planos Nacionais, por sua vez, têm uma clara dimensão técnica. Embora sejam permeados por decisões políticas e não se proponham a ser instrumentos neutros, são eles que respondem pela operacionalização das políticas públicas, detalhando tanto as ações, metas e responsáveis, quanto os mecanismos gerenciais para sua implementação. Como enfatizado no I PNPM, a Política deveria ser a linha mestra, que, de caráter mais perene, orientaria o desenvolvimento dos Planos Nacionais, mais conjunturais (BRASIL, 2004b). É no nível dos Planos que se desenvolvem mais explicitamente os elementos constitutivos da transversalidade, o que torna fundamental compreender quais são as definições apresentadas (BRASIL, 2004b; 2008; 2013).

O I PNPM (BRASIL, SPM, 2004b) assumiu a gestão da transversalidade como fundamento desse instrumento, compreendendo-a como um esforço de superação da "setorialização" das ações em nível federal, por meio de articulação horizontal e não hierárquica de todos os órgãos de governo e níveis de poder, para reorientar as ações governamentais na perspectiva de gênero e integrá-las a outras abordagens, como a igualdade racial. O II PNPM reforçou esse entendimento, destacando que a gestão e o monitoramento do plano têm relevância equivalente às próprias ações e que seu objetivo é, entre outros, "aumentar o grau de articulação entre instituições e atores", "melhorar a integração entre os órgãos setoriais" e "identificar oportunidades setoriais de investimentos em atividades específicas relativas à transversalidade" (BRASIL, 2008, p. 187).

O PNPM (2013-2015), por sua vez, identificou a transversalidade como uma orientação para ressignificar "conceitos-chave que possibilitam um entendimento mais amplo e adequado de estruturas e dinâmicas sociais que se mobilizam na produção das desigualdades" e, ainda, como uma nova estratégia "para o desenvolvimento democrático como processo estruturado em função da inclusão sociopolítica das diferenças, tanto no âmbito privado, quanto público". A sua gestão significa "a reorganização de todas as políticas públicas e das instituições para incorporar a perspectiva de gênero, de modo que a ação do Estado como um todo seja a base de políticas para as mulheres" (BRASIL, 2013, p. 10). 
As definições de transversalidade adotadas nas duas primeiras edições dos Planos enfatizam a sua gestão, por meio da integração de setores governamentais e da coordenação horizontal, especialmente em nível federal. Esse aspecto não é negligenciado no PNPM (2013-2015), no qual são propostas novas iniciativas, como a criação de mecanismos de gênero na administração direta e indireta em âmbito federal. Mas outros aspectos da gestão da transversalidade também são salientados, a exemplo da sua articulação com "dinâmicas sociais", "desenvolvimento democrático" e "inclusão sociopolítica das diferenças". A dimensão democratizante de seu significado, foi, portanto, valorizada.

Outro aspecto que ganhou maior relevância foi o estímulo à criação e ao fortalecimento de organismos de políticas para mulheres em nível subnacional, por um lado, e de espaços de participação e da relação entre Estado e sociedade civil, por outro.

No primeiro caso, a ênfase nos organismos no âmbito estadual, distrital e municipal evidencia a maior preocupação com a integração federativa na gestão da política, tema presente desde a estruturação da Política Nacional na 1a CNPM e no I PNPM (BRASIL, 2004a; b). A dificuldade de articulação de entes federativos chegou a ser apontada durante a 2ª CNPM, pela então ministra Nilcéa Freire, como uma das principais limitações da política, uma vez que o I PNPM configurava-se "praticamente um Plano do Governo Federal", remetendo-se "pouco ao pacto federativo" (BRASIL, 2007a, p. 30).

A partir da 3a CNPM, reiterou-se, também, a necessidade de que as conferências subnacionais contribuíssem para a construção de uma plataforma de políticas para mulheres nos municípios, distritos e estados, assim como para o fortalecimento dos mecanismos de gênero em nível federal (BRASIL, 2011a). O PNPM (2013-2015), por sua vez, previu que sua implementação deveria combinar a transversalidade horizontal, que envolve a relação entre os ministérios, com a vertical, engajando estados, distritos e municípios (BRASIL, 2013).

A dimensão vertical da transversalidade se tornou ainda mais central nos objetivos da 4a CNPM. Retomando uma proposta que apareceu nos debates da 3a CNPM, uma das finalidades dessa edição foi a de coletar subsídios para a construção de um Sistema Nacional de Políticas para as Mulheres, a fim de "propiciar uma maior responsabilização da atuação dos gestores públicos com a igualdade de gênero nas várias esferas de ações de governo, garantindo a transversalidade do tema" (BRASIL, 2015b, p. 26). Ressaltou-se, ainda, a importância do desenvolvimento de planos municipais e estaduais de políticas para as mulheres (BRASIL, 2015a; b; c).

Essa dimensão vertical da transversalidade, que ganhou maior relevância a partir do PNPM (2013-2015), indica uma ressignificação dos significados originais 
do gender mainstreaming no contexto nacional, em que a dimensão federativa representa, simultaneamente, potencialidade e desafio para efetivação da política para mulheres.

A articulação Estado-sociedade civil, por outro lado, esteve presente desde as primeiras edições dos Planos e da Política Nacional, como parte do fundamento de legitimação desses instrumentos. As Conferências tornaram-se relevantes arenas de negociação entre agentes governamentais e da sociedade civil, a fim de estabelecer as prioridades da área. O CNDM, por sua vez, além de responder pela definição de diretrizes para a política e pela organização do processo de conferências, integrou, juntamente com a SPM, o Comitê de Articulação e Monitoramento desde sua primeira composição.

As instâncias participativas estiveram, portanto, integradas à operacionalização da gestão da transversalidade nessa trajetória, representando uma dimensão importante para a compreensão do significado da transversalidade. Entretanto, na 4a edição, a importância conferida ao tema assumiu novos contornos, uma vez que o fortalecimento e a ampliação de espaços institucionalizados de participação e, ainda, das próprias organizações feministas, foram definidos como objetivos da conferência (BRASIL, 2015a; b; c).

É possível identificarmos, nesse percurso, uma transformação "complexificadora" dos significados atribuídos à transversalidade, em que a sua dimensão técnica é mais claramente articulada à política. Ademais, a centralidade conferida a elementos de coordenação horizontal e de técnicas de operacionalização dessa estratégia foi matizada pela incorporação, sobretudo, da problemática federativa e, em menor medida, da relação Estado-sociedade. Isso conferiu contornos específicos ao seu delineamento, com a emergência de aspectos relevantes da atuação governamental no contexto nacional.

\section{Considerações finais}

Neste artigo, buscamos analisar os significados atribuídos à transversalidade de gênero no processo de estruturação da política para mulheres no Brasil, de 2003 até 2016. Partindo de pesquisa documental, evidenciamos que a transversalidade possui um caráter processual e que sua dinâmica é indissociável das principais questões do feminismo, indo além de aspectos de gestão de políticas e de coordenação governamental, sem, contudo, excluílos. Identificamos, também, que os significados se transformaram nesse percurso, influenciados pelos desafios percebidos para a consolidação dessa 
política, a exemplo da dimensão federativa. Mas também em decorrência das reivindicações dos movimentos feministas e de mulheres.

A dimensão técnica da transversalidade foi enfatizada nos Planos Nacionais, especialmente nas duas primeiras edições, nos quais prevaleceu a temática da gestão e da coordenação governamental horizontal. Nesse sentido, buscou-se estruturar instâncias para gestão, monitoramento e avaliação de políticas na área, como o Comitê de Articulação e Monitoramento. Isso não significou, contudo, a desvinculação de uma dimensão política, expressa, sobretudo, na Política Nacional e, posteriormente, valorizada no PNPM (2013-2015). Nesse percurso, observamos a construção de uma visão política e crítica sobre as questões de gênero, a partir da qual as ações governamentais deveriam ser revistas ou estruturadas.

A gestão da transversalidade conferiu, em um primeiro momento, maior centralidade à coordenação horizontal, por meio da integração de ações de diferentes órgãos em nível federal. Posteriormente, entretanto, agregou a esse aspecto a coordenação vertical ou federativa, a exemplo da ênfase conferida à ampliação do número de organismos de políticas para mulheres em nível subnacional e na proposta mais recente de criação de um Sistema Nacional de Políticas para as Mulheres. Trata-se de uma formulação da transversalidade que ressignifica os sentidos do gender mainstreaming, tornando-o mais aderente à dinâmica federativa do país.

Igualmente, a importância da participação social para a consolidação das ações desenvolvidas foi assinalada. Isso também respondeu a um esforço de enraizamento da política, para torná-la menos suscetível às idiossincrasias contextuais, o que aponta que os significados da transversalidade se amoldaram aos desafios da institucionalização dessa política.

A valorização gradual da interseccionalidade esteve associada ao reconhecimento de que outros sistemas de diferenças interagem com o de gênero e, portanto, devem ser considerados para o alcance do objetivo da igualdade. A abertura para a pluralidade, sinalizada desde as primeiras edições das conferências, foi tensionada pela atuação de movimentos feministas e de mulheres. Destacou-se, nesse processo, o papel das conferências, que, na dinâmica cíclica com os planos, constituiu-se um espaço permanente de reivindicação e controle pela sociedade civil, impulsionando o alargamento da noção de transversalidade. Entretanto, isso não significou que a recepção do conceito de interseccionalidade tenha, efetivamente, reorganizado essa política.

Evidenciamos, ainda, a priorização da busca da garantia de direitos às "mulheres" no desenvolvimento da política, prevalecendo uma combinação de ações voltadas para a igualdade de tratamento entre mulheres e homens e a valorização das 
diferenças. Não é possível depreender, entretanto, como se pretendia, com esse enfoque, transformar os padrões de gênero de maneira mais ampla. Nesse contexto, a centralidade na "mulher" deixou pouco espaço para o desenvolvimento de uma abordagem mais radical e transformadora das relações de gênero.

Por fim, o esforço para agregar a perspectiva de gênero ao mainstream governamental resultou em uma contradição, em um contexto de constante iminência de extinção do próprio organismo criado para a coordenação dessa política. Por um lado, há, nos documentos analisados, a defesa da transversalidade como estratégia para garantir a inserção da perspectiva de gênero no curso central da ação estatal. Por outro, observa-se, principalmente nos anais das conferências, a denúncia da marginalidade dessa incorporação e a fragilidade da perspectiva da transversalidade no nível local. Essa contradição indica que a materialização da transversalidade na prática governamental diverge, em grande medida, de seu ideal, expresso nos documentos de referência da política.

Esse contraste foi evidenciado nas falas de representantes institucionais, que sublinhavam que a transversalidade era desacreditada por diversos atores governamentais. E na recorrência de abordagens instrumentalizadoras do tema, assim como na perda da radicalidade das reivindicações feministas, a exemplo do debate sobre a pobreza e sobre o aborto, respectivamente.

O exercício empreendido neste trabalho visou contribuir para uma compreensão da transversalidade atrelada à dinâmica sociopolítica, na qual a política para as mulheres se estruturou. Com isso, buscamos nos somar aos esforços que vêm sendo empreendidos para a compreensão de seus significados no contexto nacional, mobilizando reflexões de dois campos distintos, os estudos de gênero e a administração pública. Partimos do entendimento de que é a partir da construção de mediações entre esses dois campos de conhecimento que podem surgir subsídios para os avanços teóricos e práticos relativos às políticas para a igualdade de gênero.

\section{Referências bibliográficas}

BANDEIRA, Lourdes. Brasil. Fortalecimento da Secretaria Especial de Políticas para as Mulheres: Avançar na transversalidade da perspectiva de Gênero nas Políticas Públicas. Brasília: SPM, 2005.

BRASIL. Lei no 10.539, de 23 de setembro de 2002. Dispõe sobre a estruturação de órgãos, cria cargos em comissão no âmbito do Poder Executivo Federal, e dá outras providências. Diário Oficial da União, 2002.

. Lei no 10.683 , de 28 de maio de 2003. Dispõe sobre a organização da Presidência da República e dos Ministérios, e dá outras providências. Diário Oficial da União, 2003. 
. Lei no 12.888 de 20 de julho de 2010. Institui o Estatuto da Igualdade Racial; altera as Leis nos 7.716, de 5 de janeiro de 1989, 9.029, de 13 de abril de 1995, 7.347, de 24 de julho de 1985, e 10.778, de 24 de novembro de 2010. Diário Oficial da União, 2016.

Lei no 12.375 , de 30 de dezembro de 2010. Altera Lei no 10.683, de 28 de maio de 2003, e dá outras providências, e dá outras providências. Diário Oficial da União, 2003.

. Medida Provisória no 782 de 31 de maio de 2017. Estabelece a organização básica dos órgãos da Presidência da República e dos Ministérios. Diário Oficial da União, 2017.

. Plano Plurianual de Ação Governamental 2012-2015. Plano Mais Brasil. Brasília: 2011.

Secretaria de Políticas para as Mulheres. Anais da $1^{\underline{a}}$ Conferência Nacional de Políticas Públicas para as Mulheres. Brasília, 2004a.

Mulheres. Brasília, 2007a.

. Anais da $2^{a}$ Conferência Nacional de Políticas Públicas para as

Anais da 3 a Conferência Nacional de Políticas Públicas para as Mulheres. Autonomia e Igualdade para as Mulheres. Brasília: 2011a.

. Capacitação para os mecanismos de gênero no Governo Federal. Brasília: Presidência da República, 2014a.

. Decreto de 17 de janeiro de 2007. Convoca a II Conferência Nacional de Políticas Públicas para as Mulheres. Brasília: 2007. Diário Oficial da União, 2007b.

. Decreto de 19 de dezembro de 2003. Convoca a 1a Conferência Nacional de Políticas Públicas para as Mulheres. Diário Oficial da União, 2003.

. Decreto de 30 de março de 2015. Convoca a 4a Conferência Nacional de Políticas Públicas para as Mulheres. Diário Oficial da União, 2015a.

. I Plano Nacional de Políticas Públicas para as Mulheres. 2004b.

. _ _ I I Plano Nacional de Políticas Públicas para as Mulheres. 2008.

. Pensar o Brasil para o enfrentamento do racismo, do sexismo e da lesbofobia - Relatório final do grupo de trabalho para Fortalecimentos das Ações de Enfrentamento do Racismo, Sexismo e Lesbofobia no II PNPM. Brasília: SPM, 2010b.

2013.

. Plano Nacional de Políticas Públicas para as Mulheres 2013-2015.

Ano II.

. Raseam - Relatório Anual Socioeconômico das Mulheres. 2014b,

. Regimento Interno. II Conferência Nacional de Políticas Públicas para as Mulheres. Brasília: 2007c.

. Regimento Interno. 3a Conferência Nacional de Políticas Públicas para as Mulheres. Brasília: 2011b.

- Regulamento Interno - Caderno de Propostas. 4a Conferência Nacional de Políticas Públicas para as Mulheres. Brasília: 2015b. 
Texto Base. 4ạ Conferência Nacional de Políticas Públicas para as Mulheres. Brasília: 2015c.

BRonzo, Carla. Intersetorialidade como princípio e prática nas políticas públicas: reflexões a partir do tema do enfrentamento da pobreza. In: XII Congresso do Centro Latinoamericano de Administración para el Desarrollo - CLAD, Santo Domingo. Anais... Venezuela: [s.n.], 2007.

CARloto, Cássia Maria; MARIANo, Silvana Aparecida. Empoderamento, trabalho e cuidados: mulheres no programa bolsa família. Textos \& Contextos, v. 11, n. 2, p. 258-272, ago/dez. 2012.

CISNE, Mirla; Gurgel, Telma. Feminismo, Estado e políticas públicas: desafios em tempos neoliberais para a autonomia das mulheres, In: SER Social, v. 10, n. 22, p. 69-96, 2008.

CRENSHAW, Kimberle. Documento para o encontro de especialistas em aspectos da discriminação racial relativos ao gênero. Revista Estudos Feministas, v. 10, n. 1, p. 171-188, 2002.

CUNNIL-Grau, Núria. La intersetorialidad em lasnuevas politicas sociales: um acercamiento analítico-conceptual. In: Gestión y Políticas Públicas, v. XXIII, n. 1, p. 5-46, 1ㅇs semestre de 2014.

FARAH, Marta. Gênero e políticas públicas. Estudos Feministas. Santa Catarina, v. 1, p. 1-20, janeiro - abril/2004.

. Gênero. In: Dicionário de políticas públicas. 2a edição. São Paulo: FUNDAP/ UNESP, v. 1, p. 384-388, 2015.

FrANZESE, Cibele. Federalismo cooperativo no Brasil: da Constituição de 1988 aos sistemas de políticas públicas. Tese de doutorado em Administração Pública e Governo. São Paulo: FGV, 2010.

FRASER; Nancy. Feminism, capitalism, and the cunning of History. New Left Review. Londres, n. 56, p. 97-117. mar./abr. 2009.

GIBBS, Graham. Análise de dados qualitativos. Porto Alegre: Bookman, 2009.

Godinho, Tatau. Construir a igualdade combatendo a discriminação. In: Políticas públicas e igualdade de gênero. GodINHO, Tatau; SILVEIRA, Maria Lúcia da (org.). São Paulo: Coordenadoria Especial da Mulher, p. 55-64, 2004.

GuZMÁN, Virginia. La institucionalidad de género en el Estado: nuevas perspectivas de análisis. Cepal, Mujer y Desarrollo, 32, marzo 2001.

Instituto de Pesquisa Econômica Aplicada (Ipea). Avanços e desafios da transversalidade nas políticas públicas federais voltadas para minorias. In: Ipea. Brasil em desenvolvimento: Estado, planejamento e políticas públicas, v. 3, p. 779795. Brasília: Ipea, 2009.

JAHAN. Rounaq. The elusive Agenda: mainstreaming women in development. The Pakistan Development Review. 35: 4, Part II, p. 825-834. Winter, 1996.

LABRECQUE, Marie France. Transversalização da perspectiva de gênero ou instrumentalização das mulheres? Revista Estudos Feministas, Florianópolis, v. 18, n. 3, p. 901-912, dez. 2010. 
LoURo, Guacira L. Gênero, sexualidade e educação: uma perspectiva pósestruturalista. Petrópolis: Vozes, 1997

KERGOAT, Danièle. Dinâmica e consubstancialidade das relações sociais. Novos estudos - CEBRAP, São Paulo, n. 86, p. 93-103, Mar. 2010.

MARCondes, Mariana; SANDIM, Tatiana; DINIZ, Ana Paula. Transversalidade e intersetorialidade: mapeamento do debate conceitual no cenário brasileiro. Administração Pública e Gestão Social. Viçosa, v. 10, n. 1, p. 22 -33, jan./mar. 2018.

Miguel, Luis Felipe. Igualdade e Diferença. In: MigueL, Luis Felipe; BIROLI, Flavia. Feminismo e política. São Paulo: Boitempo Editorial, 2014, p. 63-77.

MonteIRO, R. F. B. L. Desafios e tendências das políticas de igualdade de mulheres e homens em Portugal. Revista Estudos Feministas. Florianópolis, v. 21, n. 2, p. $535-$ 552, Aug. 2013.

MOSER, Caroline; MOSER, Annalise. Gender mainstreaming since Beijing: a review of successes and limitations in international institutions. In: Gender and Development, v. 13, n. 2, 2005.

ORganizaÇÃo dAS NAÇões UNIDAS (ONU-MULHERES). Declaração e Plataforma de Ação da IV Conferência Mundial Sobre a Mulher. Onu-Mulheres: Pequim, 1995.

PAPA, Fernanda de C. Transversalidade e políticas públicas para mulheres no Brasil - percursos de uma pré-política. Dissertação (Mestrado em Administração Pública e Governo). Escola de Administração de Empresas de São Paulo, Fundação Getulio Vargas, São Paulo, 2012.

PEREIRA, Rosângela Saldanha et al. Transversalidade de gênero e políticas sociais no orçamento do estado de Mato Grosso. Revista de Estudos Feministas. Florianópolis, v. 18, n. 2, p. 425-450, ago. 2010.

REINACH, Sophia. Gestão transversal de políticas públicas no âmbito federal brasileiro: uma leitura inicial. Dissertação de mestrado, Escola de Administração de Empresas de São Paulo da Fundação Getúlio Vargas, São Paulo, 2013.

SANDIM, Tatiana. Mudanças recentes no programa travessia: a intersetorialidade tem se fortalecido? 2012. Dissertação de mestrado. Fundação João Pinheiro, Belo Horizonte, 2012.

ScotT, Joan. Gênero: uma categoria útil para a análise histórica. Recife: SOS Corpo, 1995.

SERRA, Albert. La gestión transversal. Expectativas y resultados. In: Revista del CLAD Reforma y Democracia, n. 32. Caracas: CLAD, 2006.

SIlvA, Tatiana D. Gestão da Transversalidade em Políticas Públicas. In:Enanpad, XXXV, 2011, Rio de Janeiro, Anais... Rio de Janeiro: Anpad, 2011.

SHAW, Jo. The European Union and gender mainstreaming: constitutionally embedded or comprehensively marginalised? Feminist Legal Studies, v.10, p. 213226, 2002. 
SouzA, Clóvis H. L. A que vieram as conferências nacionais? Uma análise dos objetivos dos processos realizados entre 2003 e 2010. In: AVRITZER, Leonardo; SouZA, Clóvis H. L. Conferências Nacionais: atores, dinâmicas participativas e efetividade. Brasília: Ipea, 2013.

WALBY, Silvia. Gender mainstreaming: productive tensions in theory and practice. Social Politics, v. 12, n. 3. p. 321-343, 2005.

\section{Mariana Mazzini Marcondes}

Doutorado em andamento em Administração Pública e Governo pela Escola de Administração de Empresas de São Paulo da Fundação Getúlio Vargas (EASP-FVG), mestrado em Política Social pela Universidade de Brasília (UnB). Especialista em Políticas Públicas e Gestão Governamental do Ministério do Planejamento, Desenvolvimento e Gestão. Contato: mariana.mazzini.m@gmail.com.

\section{Ana Paula Rodrigues Diniz}

Doutorado em andamento em Administração Pública e Governo pela Escola de Administração de Empresas de São Paulo da Fundação Getúlio Vargas (EASP-FGV), mestrado em Administração pelo Centro de Pós-Graduação e Pesquisa em Administração da Universidade Federal de Minas Gerais (UFMG). Contato: anaprdiniz@hotmail.com.

\section{Marta Ferreira Santos Farah}

Possui doutorado em Sociologia pela Universidade de São Paulo (USP). Atualmente é Professora Titular da Escola de Administração de Empresas de São Paulo da Fundação Getúlio Vargas (EASP-FGV). Contato: marta.farah@fgv.br. 